\title{
LOS CONVENIOS COLECTIVOS COMO HERRAMIENTA PARA ALCANZAR LA IGUALDAD DE GÉNERO EN EL TRABAJO. ESTUDIO DE CASO: LA INDUSTRIA QUÍMICA EN TARRAGONA
}

\author{
COLLECTIVE AGREEMENTS AS A TOOL FOR ACHIEVING GENDER \\ EQUALITY IN THE WORKPLACE. CASE STUDY: THE CHEMICAL \\ INDUSTRY IN TARRAGONA
}

\author{
Paloma Pontón Merino \\ Inma Pastor Gosálbez \\ Universidad Rovira i Virgili, Tarragona. España/Spain \\ palomaponton@gmail.com \\ inma.pastor@urv.cat
}

Recibido/Received: 27/03/2014

Modificado/Modified: 30/05/2014

Aceptado/Accepted: 27/06/2014

\section{RESUMEN}

La igualdad de género y la negociación colectiva son los elementos clave del análisis que se presenta en este artículo. Los convenios colectivos y la negociación colectiva constituyen una de las herramientas para alcanzar el objetivo de la igualdad entre mujeres y hombres en el trabajo. La incorporación de materias de igualdad en los temas de debate negociales es un asunto relativamente nuevo, que resulta clave para la igualdad laboral real. En España, desde 2007, los convenios colectivos han visto crecer exponencialmente las cláusulas relativas a estas materias. Sin embargo, esta incorporación es lenta y limitada. Los cambios en la legislación y los contenidos incorporados en los convenios no dejan de ser medidas funcionales para un sistema basado en la división sexual del trabajo que no está suficientemente cuestionado. En este texto presentamos un análisis de los convenios colectivos de la Asociación Empresarial Química de Tarragona, que demuestran estas afirmaciones.

\section{PALABRAS CLAVE}

Negociación colectiva, igualdad de género, trabajo, organizaciones.

\section{SUMARIO}

1. Introducción. 2. Contexto. 3. Marco teórico. 4. Análisis. 5. Conclusiones preliminares. Bibliografía.

\begin{abstract}
Gender equality and collective bargaining are the key elements of the analysis presented in this paper. Collective agreements and collective bargaining are some of the tools to achieve the goal of equality between women and men at work. The incorporation of equality issues in bargaining debate is something relatively new, which is crucial to reach real labor equality. In Spain, since 2007, the collective agreements that include clauses on equality have grown exponentially. Nevertheless, the incorporation of contents on equality between women and men in collective agreements is slow and limited. Changes in legislation and the contents incorporated in the agreements do not stop being functional measures for a system based on the sexual division of labor that is not sufficiently criticized.
\end{abstract}


In this paper we analyze the existing collective agreements of the Asociación Empresarial Química de Tarragona, in south Catalonia, that demonstrate these affirmations.

\section{KEYWORDS}

Collective bargaining, gender equality, work, organizations.

\section{CONTENTS}

1. Introduction. 2. Context. 3. Theoretical Framework. 4. Analysis. 5. Preliminary conclusions. References.

\section{INTRODUCCIÓN}

Esta investigación se centra en la igualdad entre mujeres y hombre en el ámbito laboral a partir del estudio de caso de la industria química de Tarragona. El sector químico es, para el área estudiada, una potencia económica muy fuerte que emplea a un alto porcentaje de personas. Tarragona tiene el complejo petroquímico más grande de España y representa una cuarta parte, $25 \%$, de la industria química española. Esta actividad ocupa de manera directa, en la provincia de Tarragona a 10.000 personas, y de manera indirecta a 4.000, desigualmente distribuidos por sexos y categorías profesionales: así, mientras que ellos son una amplia mayoría entre el personal de producción e ingeniería, con porcentajes que oscilan entre el $90 \%$ y el $100 \%$ de la plantilla; en otras categorías profesionales, como la administración, ellas representan entre el $55 \%$ y el $100 \%$ de la plantilla. Como dato positivo, no obstante, la Asociación Empresarial Química de Tarragona, (en adelante, AEQT) registra desde el año 2000 un incremento del $25 \%$ en la cifra de mujeres asalariadas en el sector químico en relación con el total de personas empleadas.

Por otra parte, los estudios de Química, Bioquímica, Ingeniera Química y estudios afines de la Universidad Rovira i Virgili de Tarragona concentran el mayor número de estudiantes de la universidad (con un 43\% de alumnado). A diferencia de lo que ocurre en este ámbito de estudios en otras universidades españolas, se trata de unos estudios donde ellas son mayoría, tanto en estudiantado (54\%) como en profesorado (Pastor, 2008). Es de destacar la fuerte presencia de mujeres ocupando cargos de dirección y de responsabilidad, al contrario de lo que ocurre en otras disciplinas, donde el scissor diagram se hace más patente.

Esta alta presencia de mujeres no se traduce, sin embargo, en el número de mujeres que finalmente trabajan en la industria química. Y menos aún entre las mujeres que ocupan cargos de dirección y responsabilidad en las empresas. De hecho, ninguna de ellas está liderada por una mujer, y sólo en un caso (BASF) una mujer (de nacionalidad alemana) forma parte del equipo directivo.

Referente a la metodología, para esta investigación se han combinado métodos de cuantitativos y cualitativos. Más allá de la revisión bibliográfica, se ha hecho un análisis documental de los convenios colectivos y acuerdos de empresa de las empresas que forman parte de la AEQT.

La muestra de empresas estudiada está formada por el total de empresas de la AEQT: 31 empresas (Carburos Metálicos SA, Dow Chemical Ibérica SL, Messer Ibérica de Gases SAU, Repsol Petróleo SA, Repsol Química SA, Repsol Exploración SA, Repsol Butano SA, Bertschi Ibérica SL, Solvin Spain SL, Asfaltos Españoles SA, Ashland industries Hispania SA, Lyondell Basell Poliolefinas Ibérica SL, BASF Española SL, BASF Sonatrach Propanchem SA, Bayer MaterialScience SL, Celanese Chemicals Ibérica SL, Clariant Ibérica 
SA, Compañía Logística de Hidrocarburos CLH SA, E.On Generación SL, ERCROS SA, Industrias Químicas Asociadas LSB SL, Nitricomax SL, Kemira Ibérica SA, Elix Polymers SL, Productos Asfálticos SA, Sekisui Specialty Chemicals Europe SL, Tarragona Power SL, Terminales Portuarias SL, Transformadora de Etileno AIE y Vopak Terquimsa SA), distribuidas en dos polígonos industriales en el área del Camp de Tarragona.

Además de este análisis documental, también se ha analizado el XVII Convenio General de la Industria Química, como convenio de referencia del sector y otros documentos de interés, como los planes de igualdad de distintas empresas de la AEQT (disponen de él el $80 \%$ de las empresas) y los Informes públicos de Responsabilidad Social AEQT de los últimos años. Cabe destacar el caso de 1 empresa que no funciona bajo la lógica de las relaciones laborales colectivas, no dispone de convenio colectivo propio, ni se acoge al convenio sectorial, sino que funciona bajo la fórmula de la asociación directa (relación laboral individual), típica de países de tradición más liberal, como Estados Unidos, de donde es dicha empresa. Según esta forma de relación, la persona trabajadora pacta individual y directamente con su empleador o persona de mando directo las condiciones de trabajo, desde los horarios de trabajo hasta la retribución. Veremos, en el apartado de análisis, cómo este particular tipo de relación laboral deja al trabajador en una situación menos ventajosa, con menos capacidad de incidencia y más dependencia del empleador. Algunos autores se han mostrado especialmente críticos con esta fórmula, como Alain Supiot (2008) quien sostiene que el mundo del trabajo sólo puede ser civilizado si el trabajador se organiza sindicalmente y negocia colectivamente.

Por otra parte, se han realizado entrevistas a representantes sindicales de una muestra del total de empresas AEQT (15 entrevistas). Las personas entrevistadas se reparten de la siguiente manera: 7 entrevistas a representantes de Unión General de Trabajadores (UGT), 7 entrevistas a Comisiones Obreras (CCOO) y 1 entrevista al sindicato minoritario CO.BAS (Sindicato de Comisiones de Base). Se ha entrevistado, también, a las personas responsables de las áreas de igualdad de estos tres sindicatos (3 entrevistas) y a un representante sindical de una empresa del sector químico, no incluida en la AEQT. En un estadio posterior de la investigación se realizarán también entrevistas a representantes de la empresa (comités de empresa, patronal, dirección, personal técnico de recursos humanos).

Partimos de la hipótesis que el avance de la incorporación de contenidos relacionados con la igualdad entre mujeres y hombres en los convenios colectivos es lento y limitado. A partir del análisis de datos y de la revisión de literatura damos argumentos teóricos y empíricos que demuestran esta lentitud y las limitaciones con las que se encuentran los convenios colectivos a la hora de traspasar sus cláusulas a la realidad de las personas trabajadoras. Para conseguir actuaciones verdaderamente dirigidas a la promoción de la igualdad se requiere un enfoque del género que no es el mayoritario en las empresas. Creemos, siguiendo a Ely y Meyerson (2000), que la consideración que tienen las empresas sobre el género y la igualdad de género es crucial a la hora de vehicular demandas o activar políticas a favor de la igualdad.

Nos planteamos como objetivo general analizar y evaluar el estado de la igualdad entre mujeres y hombres en los convenios colectivos de las empresas del sector químico del Camp de Tarragona para disponer de datos empíricos que permitan argumentar y enunciar las recomendaciones adecuadas para cada uno de los agentes responsables de la negociación en materia de igualdad de trato y no discriminación por razón de sexo. Asimismo, como objetivo secundarios pretendemos: a) tomar el pulso a la realidad negocial en materia de igualdad entre mujeres y hombres, detectando las dificultades encontradas y poniendo en valor los logros obtenidos, siendo conscientes de que a pesar de haber avanzado bastante en esta materia, todavía nos queda un largo camino por recorrer; b) a partir del análisis de los 
discursos de las personas entrevistadas y de los textos de los convenios, pretendemos establecer una tipología de las empresas, según su visión del género; y c) a partir del análisis de las materias de igualdad de género de los convenios colectivos, pretendemos establecer una tipología de cláusulas.

Igualdad de género, negociación colectiva y convenios colectivos son los elementos clave del análisis que se presenta en este artículo. El texto se organiza a partir de la estructura siguiente: en este primer apartado, justificamos el interés del trabajo, presentamos las hipótesis de investigación y el objetivo general. En segundo lugar, presentamos el contexto de la investigación a dos niveles: a) nos aproximamos a la regulación de la igualdad de género en normativas de distinto rango, haciendo especial referencia a la Ley Orgánica 3/2007 de 22 de marzo, para la Igualdad Efectiva Entre Mujeres y Hombres (en adelante, LOIEMH), como norma inspiradora de toda la regulación reciente en materia de igualdad en nuestro Estado y también en Cataluña; y b) analizamos la incorporación de materias relacionadas con la igualdad de género en la negociación colectiva y los convenios colectivos desde una perspectiva histórica. En tercer lugar, hacemos una breve referencia al marco teórico que sustenta esta investigación, explicando algunos de los conceptos clave con los que trabajamos. En cuarto lugar, presentamos el análisis documental de los convenios colectivos, con el objetivo de ver en qué se concreta la incorporación de materias relacionadas con la igualdad de género. En este análisis encontraremos ejemplos de cláusulas en materia de igualdad de género -tanto ejemplos de buenas como de malas prácticas- y estableceremos una tipología de cláusulas. También presentamos, en este cuarto apartado, un análisis de las entrevistas, que, juntamente con los textos analizados, nos permiten elaborar una tipología de las empresas según su visión de la igualdad de género. Finalmente, acabamos con un apartado de conclusiones a la luz de los datos expuestos.

\section{CONTEXTO}

\subsection{La regulación jurídica de la igualdad de género en el trabajo}

A continuación se presentan las principales aportaciones de las legislaciones española y catalana en materia de igualdad entre mujeres y hombres y la relación de este ítem con la negociación colectiva y los convenios colectivos.

Antes, resulta interesante, a modo de clarificar la jerarquía normativa española, situar los distintos conceptos con los que vamos a operar: 1) en primer lugar en esta escala jerárquica, encontramos la Constitución Española, seguida de 2) los Tratados y Convenios Internacionales, 3) las Leyes Orgánicas, 4) las Leyes Ordinarias, Decretos Legislativos, Decretos Ley y Reales Decretos (entre los cuales Estatuto de los Trabajadores), 4) Convenios Colectivos y Convenios de Empresa, 5) Ordenanzas laborales, 6) Contrato de trabajo y finalmente 7) Usos y costumbres.

\subsection{La Ley de Igualdad española}

Queremos centrar la atención en la LOIEMH ya que la consideramos la Ley por antonomasia de igualdad y abrió un nuevo camino en el ámbito de las relaciones laborales entre trabajadoras y trabajadores y empresas. Con esta Ley se pretenden "combatir todas las manifestaciones subsistentes de discriminación, directa o indirecta, por razón de sexo y promover la igualdad real entre mujeres y hombres, eliminando los obstáculos y estereotipos sociales que impiden alcanzarla” (Ley Orgánica 3/2007:12611-12645). 
A partir de la aprobación de la LOIEMH, las empresas están obligadas a respetar la igualdad de trato y oportunidades en el ámbito laboral y, con esta finalidad, deberán adoptar medidas dirigidas a evitar cualquier tipo de discriminación laboral entre mujeres y hombres, medidas que deberán negociar y acordar con los representantes de las personas trabajadoras. En el caso de empresas con plantillas superiores a 250 personas, las medidas de igualdad deberán dirigirse a la elaboración y aplicación de un Plan de Igualdad. La LOIEMH establece que transcurridos cuatro años desde su entrada en vigor, el Gobierno procederá a evaluar el estado de la negociación colectiva en materia de igualdad. Cabe destacar que este trabajo de evaluación, a fecha actual y transcurridos más de 6 años desde su entrada en vigor, se ha materializado en informes como Análisis de medidas y planes de igualdad en la negociación colectiva (UGT e Instituto de la Mujer, 2011), o artículos como "El estado de la negociación colectiva en materia de planes de igualdad" (Arenas, 2010), entre otros, pero no por parte del Gobierno, como se preveía en la LOIEMH. Debemos matizar que, siguiendo la LOIEMH, las empresas están obligadas también a fomentar y promocionar la igualdad, son sólo a garantizarla, pero de esta obligación quedan fuera las empresas con plantillas inferiores a 250 personas.

La LOIEMH dedica su Título IV a los "Planes de Igualdad"; en este Título, además, se recoge el derecho al trabajo en igualdad de oportunidades incorporando medidas de acción positiva en el acceso al empleo, la formación, la promoción, la retribución y en las condiciones laborales, situándolas en el marco de la negociación colectiva.

La LOIEMH describe el principio de igualdad de trato entre mujeres y hombres como "la ausencia de toda discriminación, por razón de sexo, o cualquier otra condición o circunstancia personal o social vinculada al sexo, bien sea directa o indirectamente, y en particular en lo referido a la maternidad, a la asunción de obligaciones familiares y al estado matrimonial o familiar y otros factores que supongan una múltiple discriminación, como la discapacidad" (Artículo 3).

Esta Ley incorpora al ordenamiento español dos Directivas relevantes en materia de igualdad de trato. Nos interesa resaltar la Directiva 2002/73, relativa a la aplicación del principio de igualdad de trato entre hombres y mujeres en lo referente al acceso al empleo, a la formación y a la promoción profesionales, y a las condiciones de trabajo. En ella, se considera la dimensión transversal de la igualdad, prestando especial atención al ámbito de las relaciones laborales.

Los avances en la incorporación de materias relacionadas con los principios de igualdad y no discriminación en las leyes han permitido que los diferentes agentes sociales que intervienen en la negociación colectiva hayan podido, también, incluirlos en el ámbito laboral. En muchos casos el papel de los sindicatos ha sido garantizar que toda la normativa en materia de igualdad haya sido reconocida y garantizada en las empresas, a través de sus convenios y su negociación colectiva. El trabajo de los sindicatos en esta línea queda plasmado en múltiples guías, recomendaciones, manuales de buenas prácticas, etc. que se han elaborado a lo largo de los últimos años en España. Igualmente, pero en una dirección distinta, también han impulsado acciones las patronales y cámaras de comercio centrándose en el liderazgo, la dirección y el emprendimiento femenino.

\subsection{La regulación jurídica de la igualdad en Cataluña}

En 1979 Cataluña aprobó su primer Estatut d'Autonomia (en adelante, EAC) que, desde la perspectiva de género, incorporó dos disposiciones a tener en cuenta. Por un lado, el 8.2 del EAC recoge las previsiones del 9.2 de la Constitución Española en lo que al principio de igualdad material se refiere, y dispone que corresponde a la Generalitat promover las 
condiciones para que la libertad y la igualdad del individuo y los grupos en que se integra sean reales y efectivas, eliminar los obstáculos que impidan o dificulten su plenitud y facilitar la participación de todos los ciudadanos en la vida política, económica, cultural y social. Por otra parte, el 27.9 acoge la competencia exclusiva de la Generalitat en materia de promoción de la mujer. El 41, establece la obligación de los poderes públicos de garantizar la igualdad de oportunidades entre mujeres y hombres en el acceso a la ocupación, en la formación, en la promoción profesional, en las condiciones de trabajo, la retribución y debe garantizar la no discriminación en el mercado de trabajo en general. Concretamente prevé que los poderes públicos deben garantizar la transversalidad en la incorporación de la perspectiva de género y de las mujeres en todas las políticas públicas para conseguir la igualdad real y efectiva y la paridad entre hombres y mujeres.

Una década más tarde, la Ley 11/1989, de 10 de julio, crea el Instituto Catalán de la Mujer (ICD, en sus siglas catalanas), como organismo especializado de la Generalitat encargado de elaborar y ejecutar todos los proyectos y las propuestas relativas a la promoción de la mujer, para hacer efectivo el principio de igualdad dentro del ámbito de competencias de la Generalitat. La misma ley crea el Consejo Nacional de les Mujeres de Cataluña (CNDC, en sus siglas catalanas), órgano consultivo del ICD. En 1998, el Decreto 92/1998, de 31 de marzo, que modifica la estructura orgánica del ICD lo adscribe al Departamento de Presidencia, redefine la Comisión Interdepartamental para la Igualdad de Oportunidades para las Mujeres y establece algunas de las funciones del CNDC. En 2005 se produce el cambio de nombre del ICD, según la Ley 11/2005, de 7 de julio, el Instituto Catalán de la Mujer pasa a denominarse Instituto Catalán de las Mujeres. Este cambio de nombre, del singular al plural, condensaba el posicionamiento institucional de las políticas de mujeres que el ICD se comprometía a promover: situar a "las mujeres" como sujetos con el derecho de gestionarse y con el derecho de reclamar que las políticas públicas se pensaran desde el reconocimiento de la diferencia entre ser hombres y mujeres en el camino hacia la igualdad efectiva. Un año más tarde, en 2006, el ICD queda adscrito al Departamento de Acción Social y Ciudadanía y amplía las funciones. En la actualidad, tras el cambio de color del gobierno de la Generalitat en 2010, el ICD continúa en el mismo Departamento, que ha cambiado su nombre por el de Bienestar Social y Familia. Como vemos, la dependencia orgánica del ICD ha sido diversa y marcada por las orientaciones políticas del gobierno en cada momento.

La acción legislativa del Parlamento de Cataluña para desarrollar normativamente esta regulación estatutaria ha sido más bien escasa y tardía. La apuesta más decidida fue la aprobación de la Ley 4/2001, de 9 de abril, que establece la obligación de evaluar el impacto de género en la elaboración de todas las disposiciones generales de la Generalitat de Cataluña. La Ley establece la obligatoriedad de incluir en la memoria de toda propuesta de disposición una valoración sobre la perspectiva de género y un informe interdepartamental de impacto de género de las medidas que establece la disposición. Esta Ley, supone un compromiso explícito con la igualdad de oportunidades entre las mujeres y los hombres y representa un importante instrumento técnico, promovido desde la Conferencia de Beijing de 1995 (centrada en la importancia del gender mainstreaming, principio de la transversalidad de género) e impulsado por la Comisión Europea, con el objetivo de avanzar en la participación de las mujeres en todos los ámbitos social, cultural, político y económico.

En 2007, el Departamento de Trabajo crea la Dirección General de Igualad de Oportunidades en el Trabajo (DGIOT), con el objetivo que "trabaje coordinadamente con los organismos impulsores de la igualdad de oportunidades del resto de Departamentos, especialmente con el Instituto Catalán de las Mujeres, cumpliendo de esta manera el principio de transversalidad para conseguir la igualdad efectiva" (Transcripción de la Sesión 
plenaria 13/11/2007: Sesión informativa sobre los ejes de actuación del Departament de Treball en materia de igualdad de oportunidades en el trabajo 355-00047/08, pp. 9-10). Esta nueva Dirección general del Departamento de Trabajo fue muestra de la voluntad del Gobierno de impulsar la igualdad de oportunidades de manera pionera en el Estado. Durante su existencia, no muy prolongada en el tiempo, la DGIOT contaba con cinco líneas estratégicas para trabajar la igualdad de oportunidades entre mujeres y hombres en el trabajo:

1. Garantizar el acceso, la presencia y la permanencia de las mujeres al mercado laboral en condiciones dignas y de calidad, en función de sus necesidades específicas.

2. Incentivar la igualdad de oportunidades en el ámbito laboral a las empresas públicas y privadas (trabajo con las empresas).

3. Impulsar una nueva cultura del desarrollo económico que permita la reorganización del tiempo y la compatibilidad entre la vida personal y laboral (conciliación).

4. Potenciar el diálogo social y la negociación colectiva como instrumento especialmente adecuado por lograr la igualdad de oportunidades al mundo del trabajo (concertación y diálogo social).

5. Impulsar acciones en el sí del Departamento de Trabajo que promueva la igualdad y sea ejemplificadora. (Transcripción de la Sesión plenaria 13/11/2007: Sesión informativa sobre los ejes de actuación del Departament de Treball en materia de igualdad de oportunidades en el trabajo 355-00047/08, pp. 11-12)

Otro instrumento para la regulación de la igualdad de género en Cataluña son los planes de políticas de mujeres de la Generalitat de Cataluña. Después de finalizar la vigencia del "Plan de políticas de mujeres del gobierno de la Generalitat de Cataluña 2008-2011", actualmente está en vigor el "Plan Estratégico de políticas de mujeres del gobierno de la Generalitat de Cataluña 2012-2015", aprobado en octubre de 2012. Sus principios orientadores son la gobernanza y la participación; y sus estrategias, el empoderamiento y la transversalidad de género. Sus objetivos se agrupan en cuatro grandes bloques:

1. Aumentar las acciones dirigidas a alcanzar la plena igualdad entre mujeres y hombres en el conjunto de la sociedad catalana.

2. Incrementar el valor y la visibilización del emprendimiento, la carrera profesional y el talento femenino en el mercado de trabajo.

3. Mejorar la coordinación interdepartamental y la cooperación interinstitucional en el ámbito de la promoción de la igualdad entre mujeres y hombres.

4. Mejorar los mecanismos para prevenir, detectar y erradicar la violencia machista.

\subsection{La incorporación de la igualdad de género en la negociación colectiva y en los convenios colectivos}

La discriminación basada en el sexo es la principal forma de discriminación y es objeto de atención de la comunidad internacional desde la Segunda Guerra Mundial (OIT, 2008:2124). En las primeras décadas del siglo XX predominaba la idea de que las mujeres eran más débiles que los hombres, física y socialmente, por lo que ciertas ocupaciones no eran adecuadas para ellas, especialmente aquellas que pudieran poner en peligro su salud y su función cuidadoras y reproductoras. Por consiguiente, entre los primeros instrumentos adoptados por la Organización Internacional del Trabajo (en adelante, OIT) están las normas relativas a los permisos y prestaciones por maternidad. Desde principios de la década de los 50, la óptica fue desplazándose hacia la promoción de la igualdad en el empleo y la igualdad de remuneración entre mujeres y hombres.

A partir de los 60 se comenzó a reflejar el reconocimiento de que la igualdad supone que las mujeres y los hombres deben compartir responsabilidades familiares (conciliación, 
corresponsabilidad). A medida que las mujeres iban conformando una mayor proporción del mercado de trabajo, la imagen del varón con un trabajo a tiempo completo como modelo representativo del trabajador clásico, el male breadwinner, iba perdiendo terreno, si bien nunca ha dejado de existir (Durán, 1986; Izquierdo, 1998). Este cambio quedó plasmado en las normas del trabajo en 1965, con la adopción por parte de la OIT de la Recomendación 123 sobre el empleo de las mujeres con responsabilidades familiares, en la que se contemplan medidas que deben adoptarse para que a las trabajadoras les sea posible conciliar sus responsabilidades sin ser discriminadas por ello.

Desde principios de los 80 , el centro del análisis de la igualdad pasó de las mujeres a las relaciones entre mujeres y hombres, y fue haciéndose más patente que todo cambio en el papel de la mujer debía ir acompañado de un cambio en el del hombre y que ello debía reflejarse en una corresponsabilidad de las tareas familiares y del hogar, es decir, una corresponsabilidad del cuidado. Siguiendo esta línea, en 1981 se adoptó el Convenio 156 y la Recomendación 165, relativos a las trabajadoras y trabajadores con responsabilidades familiares (hijas e hijos o familiares directos a cargo) con el objetivo de facilitar su empleo sin que sean discriminados por el hecho de tener estas responsabilidades.

Cuando se reflexiona sobre el principio de igualdad en relación con la negociación colectiva es habitual destacar la importancia de ésta en la consecución de la igualdad efectiva entre mujeres y hombres en el ámbito laboral. Esta asociación es comprensible, desde la perspectiva de efectividad del principio de igualdad entre mujeres y hombres, si tenemos en cuenta las tres principales funciones del convenio colectivo en las relaciones laborales (Lousada, 2008:28-29):

1. Función reguladora (en los espacios que la ley deja a la negociación colectiva). Función que sirve para implementar, a través de una adecuada regulación, el principio de igualdad en las relaciones laborales.

2. Función individualizadora (adaptando las leyes a las realidades profesionales). Función que sirve para acercar el principio de igualdad a las partes a través de los mandatos de igualdad del $\mathrm{CC}$, generando un efecto pedagógico y un doble efecto legitimador de la negociación colectiva al implicarse en la implantación de la igualdad, y del principio de igualdad al reforzarse en el ámbito de negociación colectiva.

3. Función compensadora frente a la posición de mayor poder del empresario en las relaciones individuales de trabajo. Función que justifica incidir sobre los poderes del empresario, bien limitando el uso de esos poderes, cuyo abuso suele ser causa de discriminaciones, bien implicando esos poderes en la consecución de la igualdad, es decir, creando condiciones de igualdad real.

Sin embargo, la importancia de la negociación colectiva en la consecución de la igualdad efectiva entre mujeres y hombres en las relaciones laborales contrasta con la no implicación de muchos convenios colectivos y con la existencia de muchas discriminaciones, resultado de factores como la escasa participación femenina en las mesas de negociación, la deficiente preparación de los negociadores colectivos, la relegación de la igualdad frente a los temas retributivos o el arrastre de normas arcaicas procedentes de situaciones pasadas.

Resumiendo, nos encontramos con una realidad que no cumple los propósitos de la negociación colectiva para la consecución de la igualdad atendiendo a la idoneidad, a los efectos de alcanzar tales propósitos, de sus funciones reguladora, individualizadora y compensadora. Y con la dificultad para resolver esa situación por medio de los propios agentes sociales. Lo que nos conduce a la intervención legal, que ha operado en dos líneas de actuación prioritarias: el fomento de la igualdad y la sanción de la discriminación (Lousada, 2008:29-30). 
En España, según apunta Alemany (2006) los convenios colectivos que incluyen alguna cláusula que haga referencia a la igualdad de oportunidades no son aún mayoritarios. No obstante, se observa que esta materia se ha ido incorporando progresivamente $\mathrm{y}$, en consecuencia, en los últimos años, existe un mayor número de convenios colectivos que contienen cláusulas referidas a la igualdad. Sin embargo, el incremento del número de convenios que incluyen este tipo de cláusulas no significa obligatoriamente que el tratamiento de dicha temática haya ganado en profundidad y detalle. Sabemos que cantidad no es sinónimo de calidad. En el apartado IV presentamos el análisis de los convenios colectivos, con el objetivo de ver en qué se concreta la incorporación de materias relacionadas con la igualdad de género. En este análisis encontraremos ejemplos de cláusulas en materia de igualdad de género, tanto ejemplos de buenas como de malas prácticas, y estableceremos una tipología de cláusulas. También presentamos, en este cuarto apartado, algunos resultados preliminares de las entrevistas, que nos permiten elaborar una tipología de las empresas según su visión del género y la igualdad de género.

\section{MARCO TEÓRICO}

Merece la pena hacer un breve inciso para recuperar algunos aspectos teóricos e históricos sobre los conceptos con los cuales trabajamos. La "negociación colectiva" es entendida por la OIT como el instrumento mediante el cual las personas trabajadoras, directamente o a través de sus representantes sindicales, establecen con la patronal las condiciones de trabajo mediante un proceso de diálogo o negociación. En otras palabras, es la actividad o proceso encaminado a la conclusión de un contrato o acuerdo colectivo.

Una de las definiciones más citadas de negociación colectiva es la de Windmuller (1989: 15-16): "El proceso de toma de decisiones entre partes que representan los intereses de los empleadores y empleados. El objeto primordial es la negociación y aplicación continua de un conjunto de reglas pactadas que regulan las condiciones reales y de procedimiento de las relaciones de trabajo y determinan la relación entre las partes en este proceso". Es decir, la negociación colectiva instituye normas sobre las condiciones de empleo.

Desde el enfoque sociológico, una de las primeras obras interesantes sobre negociación colectiva es la de Beatrice y Sidney Webb, La Democracia Industrial, de principios del siglo pasado, en la cual desarrollan la tesis de la negociación colectiva como uno de los métodos de que se valen los sindicatos para mejorar las condiciones de sus afiliados. En lugar de que cada trabajador negocie individualmente con la dirección de la empresa la venta de su trabajo, el sindicato la negocia en nombre de todas las personas trabajadoras.

La negociación colectiva es, también, un ámbito importante para la promoción de la igualdad de oportunidades en el trabajo. Mediante este proceso se pueden asegurar algunas condiciones básicas para la igualdad. Entre éstas, que exista una remuneración igual para un trabajo de igual valor, la garantía y la ampliación de la protección legal a la maternidad, así como otros derechos que promuevan un mayor equilibrio entre el ejercicio de la maternidad y la paternidad y el trabajo y las responsabilidades familiares.

Por su parte, el "convenio colectivo" constituye la norma laboral por antonomasia. A diferencia de la Ley o de la propia Constitución, el convenio colectivo encierra un componente democratizador en la conformación del Derecho, puesto que permite la intervención directa en su creación a los sujetos a quienes va dirigida la norma, los propios sujetos protagonistas del escenario laboral: empresarias y empresarios y representantes de las trabajadoras y trabajadores (Erro y Sanz de Pablo, 2009:16-17). 
En otro orden de cosas, cabe clarificar algunos conceptos como son género y principio de igualdad de género. En primer lugar, conviene conceptualizar el género, dada la importancia en relación a la igualdad de trato de mujeres y hombres y la controversia que gira entorno a este concepto. Si recogemos la definición de la Unión Europea (Comisión Europea, 1998), género queda delimitado de la siguiente forma: "Concepto que hace referencia a las diferencias sociales (por oposición a las biológicas) entre hombres y mujeres que han sido aprendidas, cambian con el tiempo y presentan grandes variaciones tanto entre diversas culturas como dentro de una misma cultura". Por otro lado, el género ha sido ampliamente conceptualizado desde las ciencias sociales, la literatura existente es vastísima: numerosas autoras han trabajado en ello, desde las clásicas Simone de Beauvoir o Margaret Mead a la actual Beatriz Preciado, representante de la perspectiva posmoderna.

En segundo lugar, estamos de acuerdo en que el "principio de igualdad de género" garantiza el reconocimiento de la igualdad formal que implica la prohibición normativa o legal de discriminar a una persona. De hecho, la igualdad de género ha sido recogida en todos los ámbitos jurídicos como principio fundamental (en las Declaraciones de los Derechos Humanos y en numerosos tratados y pactos de Naciones Unidas, Unión Europea, Consejo de Europa y otras organizaciones internacionales). En el ámbito estatal este principio también ha sido ampliamente recogido en la Constitución Española, en los estatutos de las Comunidades Autónomas y en el Estatuto de los Trabajadores. El contenido del derecho fundamental a no ser discriminado por razón de sexo puede comprenderse según un modelo de tres escalones (Rey, 2000): la prohibición de discriminaciones directas, la prohibición de discriminaciones indirectas, y la licitud y exigencia de medidas de acción positiva para lograr la igualdad de oportunidades de mujeres y hombres.

\section{ANÁLISIS}

Como avanzábamos en la metodología, esta investigación se apoya en dos elementos clave para la consecución de sus objetivos. Por un lado, los convenios colectivos de las empresas de la muestra (13 empresas disponen de convenio de empresa, un 42\% del total), a los que se les ha sumado el XVII Convenio General de la Industria Química (convenio sectorial), por dos motivos: 1) es el convenio de referencia para todas las empresas del sector; y 2) es el documento al que se remiten la mayoría de convenios analizados cuando no se hace ninguna aportación propia des del convenio de empresa o cuando las empresas no disponen de convenio propio.

Además, algunas de las empresas han añadido acuerdos de empresa, anexos a los convenios, que también se han tenido en consideración para este análisis, así como los planes de igualdad de las empresas que disponen de él (un 80\%), y los Informes de Responsabilidad Social AEQT de los últimos años

Por otro lado, se ha entrevistado a representantes de las personas trabajadoras de las empresas AEQT, como agentes clave en el proceso de negociación y elaboración de los convenios colectivos y a otros agentes importantes que han tomado parte de la elaboración de los planes de igualdad. En total, se han realizado 19 entrevistas. Previamente, se ha validado el modelo de entrevista con un pre test a 1 representante sindical de una empresa del sector químico que no forma parte de la AEQT, el Consorcio de Aguas de Tarragona. A partir del análisis de las entrevistas se propone establecer una tipología de empresas, en función de su visión del género y la igualdad de género. 
Una primera lectura que podemos hacer de las entrevistas, sin entrar en los contenidos, es que todos los representantes de las personas trabajadoras en todas las empresas analizadas son hombres. Sí que encontramos, en cambio, mujeres representando a la parte de la empresa. Vemos, pues, que se cumple lo que avanzábamos en el apartado B del epígrafe II cuando apuntábamos a la escasa participación femenina en las mesas de negociación como factor que dificulta el avance en la igualdad entre mujeres y hombres en las empresas. A continuación presentamos con más detalle estos dos niveles de análisis.

\subsection{La igualdad de género en los convenios colectivos}

A partir del análisis de los 13 convenios de las empresas parte de la AEQT, del XVII Convenio General de la Industria Química y de los planes de igualdad, hemos organizado las materias referentes a la promoción de la igualdad entre mujeres y hombres que incluyen según la siguiente clasificación:

1. Cláusulas sobre acceso al empleo, la contratación y la promoción en la empresa

2. Cláusulas sobre maternidad, paternidad y salud laboral

3. Cláusulas sobre clasificación profesional y retribución salarial

4. Cláusulas sobre conciliación de la vida profesional, personal y laboral

5. Cláusulas sobre violencia de género

6. Cláusulas sobre acoso sexual y acoso por razón de sexo

En los siguientes subapartados trataremos en profundidad estos seis tipos de materias y mostraremos ejemplos de buenas y malas prácticas, en tanto que supongan una mejora o un avance para la situación de las mujeres en la empresa o no.

\subsubsection{Acceso al empleo, la contratación y la promoción en la empresa}

Por lo que se refiere al acceso al empleo, la LOIEMH modificó el Artículo 4 del Estatuto de los Trabajadores (que podía dar lugar a discriminaciones, ya que la orden de prohibición de discriminación en el acceso al empleo podía chocar con el derecho a la libre elección del candidato por parte del empleador), otorgando permiso expreso para "establecer exclusiones, reservas y preferencias en las condiciones de idoneidad, tengan preferencia para ser contratadas las personas del sexo menos representado en el grupo o categoría profesional de que se trate". Así, la LOIEMH propone medidas de acción positiva para favorecer el acceso al empleo de las mujeres, entendiendo que éstas fomentan el acceso de las mujeres en igualdad de condiciones, especialmente en sectores y ocupaciones donde están infrarrepresentadas. Esta propuesta de la LOIEMH, sin embargo, ha tenido escaso seguimiento en los convenios colectivos (García Quiñones, 2011:10-23). Se demuestra que entre el compromiso formal de desarrollar medidas de acción positiva y la materialización de estas medidas, existe una distancia importante.

Cuando hablamos de acceso al empleo, debemos diferenciar entre dos momentos: las ofertas de empleo y los procesos selectivos. Referente las ofertas, hay que hacer notar que ya en éstas pueden darse discriminaciones: una oferta sexista, que responda a estereotipos de género, precede a una contratación que también es sexista. En los convenios colectivos analizados, encontramos algunas buenas prácticas para evitar la discriminación en sus cláusulas que merece la pena citar:

a. Garantía de participación de los representantes de los trabajadores y trabajadoras en la configuración de las ofertas de trabajo.

b. Obligación de revisión de las ofertas de trabajo y redacción de un informe acerca del posible carácter discriminatorio de la oferta. 
c. Creación de una Comisión de Contratación basada exclusivamente en la cualificación del trabajador o trabajadora

d. Inclusión en los convenios colectivos del texto de la LOIEMH de la voluntad de promover el principio de igualdad de oportunidades y no discriminación por razón de sexo, removiendo los obstáculos que puedan incidir en el no cumplimiento de la igualdad de condiciones entre mujeres y hombres.

e. Fomento del uso del lenguaje no sexista, garantizando la presencia de la mujer, de modo que toda expresión que defina una actividad o condición se utilizará en el sentido compresivo de las personas de ambos sexos.

f. Previsiones de que, en igualdad de condiciones, tengan preferencia para ser contratadas las personas de sexo menos representado en el grupo o categoría profesional.

g. Publicidad de nuevas contrataciones, adecuación de los requisitos exigidos a las funciones descritas para su categoría profesional, aseguramiento de la objetividad y no discriminación.

h. Creación de una Comisión para la Igualdad.

Es difícil, no obstante, comprobar que en el momento previo a la contratación se garantice la igualdad de oportunidades entre mujeres y hombres, en un momento en el cual las personas aún no forman parte de la plantilla $\mathrm{y}$, por lo tanto, no están afectadas por el convenio. Referente a la contratación, queremos citar la siguiente cláusula que nos parece útil para lograr el objetivo de igualdad en el trabajo:

"Constitución de una Comisión Paritaria de Interpretación y Vigilancia del que formará parte un representante de los trabajadores".

El momento de la contratación es, precisamente, lo que en algunas entrevistas ha salido a la luz como lugar de discriminaciones difíciles de controlar. Transcribimos el caso más grave y extremo, en el cual un representante cita a su director de recursos humanos:

(...) yo he oído cómo el director de recursos humanos le decía a la hija de un compañero que venía a una entrevista para operario, que no hacía falta que perdiera el tiempo en el proceso, que la empresa no quería mujeres operarias, que la llamaban porque todos tenían derecho a optar al puesto, pero que no la iban a coger. (Transcripción Representante Sindical 3)

Las discriminaciones en el ámbito de la promoción tienen una incidencia directa en la "segregación vertical" en la empresa. A pesar de ser un ámbito de suma importancia, es prácticamente nula la existencia de cláusulas en los convenios colectivos que aporten una perspectiva de género a la promoción en el trabajo. Destacamos sólo una cláusula:

"Previsiones de que, en igualdad de condiciones, tengan preferencia para el ascenso las personas de sexo menos representado en la categoría profesional de que se trate".

\subsubsection{Maternidad, paternidad y salud laboral}

Tanto la maternidad, la paternidad como la salud laboral son materias que se encuentran reguladas por el Estatuto de los Trabajadores (Artículo 48 y Artículo 48bis). Estos derechos existen más allá de que estén contemplados o no en los convenios. Sin embargo, el hecho de que los convenios colectivos los contemplen asegura un mayor conocimiento por parte de las personas afectadas y demuestra un interés por parte de la empresa. Al tratarse de unos derechos superiores, son de obligado cumplimiento para las empresas. No obstante, éstas podrían mejorarlos, ampliarlos o adaptarlos a sus especificidades. La realidad de los convenios colectivos demuestra que cumplir con los mínimos legales parece suficiente a la mayoría de empresas. En la mayoría de convenios se repite textualmente lo que dispone el 
Estatuto de los Trabajadores, e incluso existen convenios que no contienen regulación alguna sobre la suspensión por maternidad o paternidad.

Destacamos un caso de convenio en el que sí se mejora el mínimo legal, aunque sólo en el caso de la paternidad, no de la maternidad:

"La empresa complementará la prestación por paternidad con 3 días naturales de licencia por nacimiento de hijo o hija (...). Esta licencia se ampliará hasta 4 días si el nacimiento tuviese lugar fuera de la residencia habitual del trabajador; y hasta 5, en el supuesto que se encuentre en comisión de servicio desplazado fuera de España".

En España, el permiso por maternidad es de 16 semanas ininterrumpidas, ampliables a 2 semanas más por cada hijo en caso de embarazo múltiple, 6 de estas semanas son de descanso obligatorio. En cuanto a la paternidad, el permiso tiene una duración de 13 días, ampliables a 2 días más por cada hijo en caso de embarazo múltiple. En ambos casos, los trabajadores que se acogen a estos permisos tienen un subsidio del 100\% de su sueldo base, y en algunos convenios se prevé que "la empresa complementará hasta el 100\% del salario real". Es interesante destacar que el porcentaje de hombres que usan el permiso de paternidad es muy pequeño, aún tratándose de un permiso pagado, que no hace falta que lo cedan las mujeres, y que si no se usa, se pierde (Pontón y Pastor, 2013).

\subsubsection{Clasificación profesional y retribución salarial}

Encontramos, en algunos convenios, claros ejemplos de malas prácticas en sus clasificaciones profesionales. Por ejemplo: el sistema de clasificación aparece solamente en masculino, tanto las categorías como sus definiciones o las categorías laborales de rango superior aparecen en masculino, y las inferiores, en femenino y masculino o neutro. Es importante el uso de un lenguaje no sexista, de lo contrario se podría entender que algunas categorías superiores estuvieran reservadas al colectivo masculino, fijando un "techo de cemento" (Dilla, 2011:34-39) para las mujeres. Además, el uso de un lenguaje no sexista viene dictado por la LOIEMH.

Por lo que se refiere a la retribución salarial, observamos, en diversos convenios, algo que viene repitiéndose de forma generalizada en el mercado de trabajo, que es la mayor retribución a las actividades típicamente masculinas. Es decir, el valor del trabajo masculino sigue siendo mayor. Vean la siguiente tabla salarial:

Tabla 1: Tabla salarial para el período 2011-2014 de la empresa Asfaltos Españoles SA

\begin{tabular}{|l|l|l|l|l|}
\hline Nivel & $\begin{array}{l}\text { Sueldo base 15 } \\
\text { pagas }\end{array}$ & $\begin{array}{l}\text { Sueldo base } \\
\text { mensual }\end{array}$ & Hora ordinaria & Hora extraordinaria \\
\hline 5 & $29.406,47$ & $1.960,43$ & 18,14 & 22,32 \\
\hline 6 & $31.177,57$ & $2.078,50$ & 19,18 & 23,60 \\
\hline
\end{tabular}

Fuente: Elaboración propia a partir de datos del VII Convenio colectivo de la empresa Asfaltos Españoles SA

El nivel 5 corresponde a la categoría profesional "administrativo/a", mientras que el nivel 6 corresponde a "oficial cualificado/a". Para ambas categorías la definición es idéntica: "Titulación/aptitudes profesionales: formación a nivel de grado medio o superior en formación profesional o conocimientos y experiencia equivalentes según el parecer de la dirección".

Debemos recordar que el Estatuto de los Trabajadores establece que "el empresario debe pagar por la prestación de un trabajo de igual valor la misma retribución, satisfecha directa o indirectamente, y cualquiera que se a la naturaleza de la misma, salarial o extrasalarial, sin 
que pueda producirse discriminación alguna por razón de sexo en ninguno de loes elementos o condiciones de aquella" (Artículo 28). Así pues, el principio de igualdad de retribución debe aplicarse tanto al salario como a los complementos extrasalariales. No obstante, la brecha salarial, gender pay gap, entre hombres y mujeres es una realidad. Si bien es cierto que en los últimos años se han producido avances indiscutibles, también lo es que en ese proceso de cambio se siguen identificando manifestaciones de desigualdad que, con el transcurrir de los años, las transformaciones sociales o la acción política no han sido capaces de reducir. La diferencia salarial entre hombres y mujeres es una de ellas. Los hombres perciben de media más salario en todas las regiones del mundo (Anker, 1997). En informes recientes se sostiene que la brecha salarial en el mundo se encontraría de media en torno a un $15,6 \%$ (Confederación Internacional Sindical, 2008), con unos valores que oscilarían entre un $30 \%$ y un $10 \%$ según los países (OIT, 2008b). Los últimos datos publicados por EUROSTAT reflejan que las mujeres españolas cobran de media un $16,2 \%$ menos que sus compañeros (UGT, 2013:16-31).

Las causas de esta brecha salarial son múltiples, diversas, complejas e interconectadas. Una de las causas a las que algunos autores apuntan (Serrano, 2014) son el tipo de ocupación, una clasificación laboral discriminatoria o la existencia de complementos salariales también discriminatorios. No obstante esta realidad y la importancia del principio de igualdad de remuneración, la regulación de algunos complementos salariales (antigüedad, destino, presencia, pagas extraordinarias, prolongación de jornada, etc.) no tienen la suficiente presencia en los convenios colectivos.

Tomamos como ejemplo uno de los convenios, en el que, en el apartado dedicado a componentes salariales funcionales se detallan las siguientes primas: prima de mando y especial responsabilidad; de peligrosidad, toxicidad o penosidad; de horario no flexible; de horario especial; de disponibilidad. Si analizamos en detalle estas primas, vemos que las mujeres quedan excluidas de muchas de estas primas por su condición de principales responsables en el ámbito doméstico y familiar. Es decir, son características propias del trabajo masculino, y muy centradas aún en una cultura del trabajo presencialista. Estos complementos salariales pueden llegar a suponer entre 1.000 y 7.000 euros más al año, suponiendo un agravio comparativo importante para muchas mujeres que no pueden acceder a estos pluses. Aunque factores como la presencia, la disponibilidad, la puntualidad, la antigüedad, etc. puedan parecer objetivos, no olvidemos que responden a factores sociales y culturales, que las empresas no se cuestionan ni revisan, y que pueden comportar graves desigualdades.

\subsubsection{Conciliación de la vida profesional, personal y laboral}

La conciliación de la vida laboral, familiar y personal fue abordada por la OIT, por primera vez, en 1965. Este organismo dirigió a los Estados Miembros una recomendación sobre el empleo de las mujeres con responsabilidades familiares (Recomendación 123, de 22 de junio de 1965, no vinculante) donde advertía que "en muchos países son cada vez más numerosas las mujeres que trabajan fuera del hogar formando parte integrante y esencial de la fuerza de trabajo, que muchas de esas mujeres tienen problemas especiales originados en la necesidad de conciliar su doble personalidad familiar y profesional y que muchos de los problemas especiales que deben afrontar las mujeres con responsabilidades familiares no son problemas exclusivos de las trabajadoras, sino de la familia y de la sociedad en su conjunto", con ello se reconocía la necesidad de una adaptación social continua para resolver esos problemas de forma que sea compatible con la mejor conveniencia de todos los interesados. 
Después de ésta vinieron múltiples intervenciones legislativas por parte de la OIT. Por citar sólo una, el Convenio 156 sobre los trabajadores y trabajadoras con responsabilidades familiares. Este Convenio subraya que "los Estados Miembros reconocen que para lograr la plena igualdad entre el hombre y la mujer es necesario modificar el papel tradicional tanto del hombre como de la mujer en la sociedad y en la familia".

Asimismo, la Unión Europea aborda la regulación de la maternidad y la conciliación de la vida laboral, familiar y personal a través de diversos instrumentos jurídicos, son algunos ejemplos la Directiva 96/34/CE del Consejo, de 3 de junio de 1996 relativa al Acuerdo marco sobre el permiso parental, en el que se establecen las disposiciones mínimas para facilitar la conciliación de las madres y los padres con empleo remunerado; o la Directiva 2006/54/CE, de 5 de julio de 2006, del Parlamento Europeo y del Consejo, relativa a la aplicación del principio de igualdad de oportunidades e igualdad de trato entre hombres y mujeres en asuntos de empleo y ocupación. En España, la Ley de Conciliación (Ley 39/1999) es la primera norma que introduce la noción de conciliación en el ordenamiento laboral. Posteriormente, ésta fue modificada por la Ley de Igualdad.

El tema de la conciliación ocupa un espacio propio dentro de la mayoría de convenios analizados. En algunos de los redactados se prevén circunstancias adicionales a las dispuestas en la Ley que permiten la ausencia del trabajador durante horas o días, sin disminución de salario, para que pueda atender a obligaciones ligadas a su cuidado o el de sus familiares. Destacamos algunas cláusulas:

"Ampliación de la duración en el caso de las excedencias familiares, equiparando la excedencia por cuidado de familiares hasta el segundo grado, pudiendo ser disfrutadas ambas por un período de 3 años".

"Ampliación del derecho a solicitar una reducción de la jornada de trabajo diaria, con la disminución proporcional del salario, para el cuidado de menores de hasta 12 años (en lugar de los 8 que prevé la Ley)".

"Permiso para acompañar a familiares a consulta médica, ya sean descendientes, personas dependientes o discapacitadas".

"Derecho a ausentarse por asistencia a terapias de reproducción asistida y para realizar los trámites de una adopción internacional”.

"Posibilidad de compatibilizar el teletrabajo con la situación de permiso por maternidad a tiempo parcial en las últimas cuatro semanas de este permiso".

Este último aspecto, el teletrabajo, creemos que es innovador y positivo, ya que facilita en gran medida la conciliación. Aunque hacemos notar que en el redactado de la cláusula, sólo se incluye el permiso por maternidad, dejando fuera el permiso por paternidad.

La flexibilidad horaria de entrada y salida también es un factor que facilita la conciliación. En la mayoría de los convenios analizados se prevé una flexibilidad de entre $30 \mathrm{~min}$ y $1 \mathrm{~h}$ $30 \mathrm{~min}$. Sin embargo, como vemos en el siguiente fragmento, algunos puestos de trabajo quedan excluidos de esta medida. Podemos observar que se excluye a las personas secretarias, que son precisamente un sector altamente feminizado:

"Entre los puestos de trabajo que no podrán realizar horarios flexibles están los siguientes: Área de sistemas de información, Conductores, Servicios Generales, Secretarios/as".

\subsubsection{Violencia de género}

Acorde con la literatura existente sobre la materia, apreciamos también en los convenios analizados, que la negociación colectiva no ha puesto especial atención a la particular situación laboral de las trabajadoras víctimas de violencia de género. La mayoría de convenios que incluyen previsiones sobre la materia se limitan a reproducir de forma 
mimética el texto legal, a sintetizar el conjunto de derechos y previsiones legales, o aluden al "deseo de dejar constancia de la incorporación" al convenio colectivo de las cuestiones establecidas en la Ley 1/2004 de Medidas de Protección Integral contra la Violencia de Género (en adelante, LOMPIVG).

En líneas generales, los convenios recogen los derechos de las mujeres trabajadoras víctimas de la violencia de género a través de tres mecanismos: 1) mediante la articulación de una cláusula referida exclusivamente a los citados derechos; 2) a través de su inclusión en los derechos relacionados con la conciliación entre la vida laboral y familiar; y 3) tratando los citados derechos por separado e insertando cada uno de ellos dentro de la condición laboral correspondiente como una causa más de posible ejercicio del derecho de que se trate.

En la mayoría de convenios colectivos se establecen medidas como las siguientes:

a. La mejora de las condiciones de ejercicio de los derechos a la movilidad geográfica, al cambio de centro de trabajo, a la suspensión de la relación laboral con reserva de puesto de trabajo y a la extinción del contrato de trabajo.

b. El establecimiento de nuevas fórmulas de acomodación razonable de las obligaciones laborales, como la posibilidad de movilidad funcional.

c. La concreción del derecho a ausentarse de la trabajadora víctima de violencia de género en un específico permiso con posible retribución.

d. El establecimiento de medidas económicas.

e. El establecimiento de medidas de salud.

Podemos destacar la cláusula del siguiente convenio, en la empresa adquiere un compromiso con la víctima que va más allá de las medidas establecidas legalmente:

"Las medidas que en estas circunstancias la empresa pone a disposición de sus empleados/as consisten en: prestación a cargo de la empresa de apoyo psicológico (...), apoyo médico (...), apoyo jurídico (...), apoyo laboral ofreciendo la mayor flexibilidad en materia de horarios, jornadas, vacaciones, licencias, permisos retribuidos (...), ayudas económicas a fondo perdido para los gastos ocasionados de la necesidad de alquiler o compra de vivienda, para los casos de movilidad geográfica, cuando la víctima opte por solución como mejor forma para resolver su problema".

No obstante, es difícil encontrar en los convenios experiencias novedosas y creativas. Por el contrario, predomina la reproducción de los textos legales. Nos encontramos con una falta de experiencia en las mesas de negociación en materia de derechos laborales de las víctimas de violencia de género ya que, antes de la LOMPIVG, eran muy escasos los convenios donde se regulaban derechos a favor de las trabajadoras víctimas de violencia de género (Mingo, 2007:23-129). Los convenios, en consecuencia, se enfrentan a la tendencia negocial de no regular la materia. Sí que es cierto, no obstante, que desde la entrada en vigor de la LOMPIVG se ha incrementado notablemente tanto el número de convenios como la trascendencia de los contenidos.

Un aspecto a destacar en este punto es que en los convenios no se incluye la posibilidad de que la violencia de género se de en la propia organización, asumiendo que la violencia de género se da fuera del puesto de trabajo, en concreto, en el ámbito familiar. Tomamos el siguiente ejemplo extraído de un convenio, en que se identifica claramente la violencia de género con aquella violencia ejercida dentro del ámbito privado, doméstico y familiar, excluyendo los casos de víctimas de violencia de género en los que el agresor es una persona desconocida, un/a colega del trabajo, etc.:

"Se entiende por violencia de género la realizada sobre un empleado/a, así como a sus hijos o hijas que convivan con él, siempre que el agresor sea una persona con quien el empleado/a mantenga en el momento que se solicitara la protección, una relación de 
parentesco o afectividad (cónyuge, ex cónyuge, pareja de hecho, ex pareja de hecho o familiar de cualquier grado)".

\subsubsection{Acoso sexual y acoso por razón de sexo}

El acoso sexual ha sido definido por la Directiva 2006/54/CE como "la situación en la que se produce cualquier comportamiento verbal, no verbal o físico no deseado, de índole sexual, con el propósito o el efecto de atentar contra la dignidad de una persona, en particular cuando se crea un entorno intimidatorio, hostil, degradante, humillante u ofensivo". España cuenta con la LOIEMH, que en su Artículo 7, hace referencia al concepto de acoso sexual reproduciendo las mismas palabras que la Directiva europea antes citada.

Si seguimos en el ámbito laboral español, el Artículo 4.2 de la Ley del Estatuto de los Trabajadores recoge como derecho laboral básico en la relación de trabajo "el respeto de su intimidad y a la consideración debida a su dignidad, comprendida la protección frente al acoso por razón de origen racial o étnico, religión o convicciones, discapacidad, edad u orientación sexual, y frente al acoso sexual y al acoso por razón de sexo". Por lo tanto, es causa justa para la extinción del contrato de trabajo por voluntad de la trabajadora o trabajador por incumplimiento grave por parte del empresario o empresaria de su obligación de protección frente a esas violaciones de su dignidad (Artículo 50.1c). En base a la infracción de la persona trabajadora, se consideran incumplimiento grave y culpa del trabajador y, por tanto, causa de despido disciplinario, "el acoso por razón de origen racial o étnico, religión o convicciones, discapacidad, edad u orientación sexual y el acoso sexual o por razón de sexo al empresario o a las personas que trabajan en la empresa" (Artículo 54.2).

Finalmente, la LOIEMH (Artículo 7) nos da las definiciones de acoso sexual y acoso por razón de sexo (o acoso sexista). Define el acoso sexual como "cualquier comportamiento, verbal o físico, de naturaleza sexual que tenga el propósito o produzca el efecto de atentar contra la dignidad de una persona, en particular cuando se crea un entorno intimidatorio, degradante u ofensivo"; y el acoso por razón de sexo como el "comportamiento realizado en función del sexo de una persona, con el propósito o el efecto de atentar contra su dignidad y de crear un entorno intimidatorio, degradante u ofensivo".

La negociación colectiva constituye un buen instrumento para luchar contra el acoso sexual y sirve como complemento a lo redactado en la LOIEMH (Sobrino, 2011:158-165). Como apunta esta autora, sería interesante que los convenios tuvieran presentes una serie de cuestiones con el propósito de hacer frente al acoso, y que asumieran el contenido de la LOIEMH y lo ampliaran. En los convenios es inusual encontrar ejemplos que vayan más allá de lo descrito en las Leyes. Para citar un ejemplo de buenas prácticas, recogemos el texto de un convenio en el que sí se dedica un amplio capítulo a la prevención de las situaciones de acoso moral, sexual y por razón de sexo, definiéndolos y estableciendo un amplio catálogo de conductas posibles:

"Las insinuaciones y comentarios molestos, humillantes de contenido sexual; los comentarios obscenos, proposiciones de carácter sexual, directas o indirectas; las cartas o notas con contenido sexual que propongan, inciten o presionen a mantener relaciones sexuales; la insistencia en comentarios despectivos $\mathrm{u}$ ofensivos sobre la apariencia $\mathrm{o}$ condición sexual de la persona trabajadora; los tocamientos, gestos obscenos, roces innecesarios; toda agresión sexual".

Esta lista es sumamente positiva, ya que permite a las personas trabajadoras comprender, más allá de la definición, los casos concretos y similares en los que se incurre en acoso sexual. Otro ejemplo positivo es la voluntad expresa en uno de los convenios analizados de: 
“Elaborar una 'Guía explicativa sobre Conductas de Acoso' para definir dichos comportamientos y prevenir los mismos dentro de nuestro entorno laboral".

También es un ejemplo de buenas prácticas, la inclusión en los convenios colectivos de una cláusula tomada de uno de ellos, que indica que:

"No es necesario que dichas acciones se desarrollen durante un tiempo prolongado o que se repitan sucesivamente para poder ser consideradas como acoso sexual; una sola acción, por su gravedad, puede ser constitutiva de acoso sexual".

\subsection{Una propuesta de tipología de empresas según su visión del género}

Podemos clasificar a las empresas según su visión del género y de la igualdad de género. Hemos establecido una tipología triple: tres maneras distintas de considerar las diferencias entre hombres y mujeres, siguiendo pero adaptando a la realidad analizada, una clasificación elaborada por Ely y Meyerson (2000) para el caso norteamericano.

El primer enfoque se basa en una visión liberal e individualista de la sociedad y, por ende, de las organizaciones. Se supone que las personas promocionan y descienden de categoría por sus propios méritos. Se entiende el género como sinónimo de sexo biológico. Según este punto de vista, los hombres y las mujeres tienen un acceso igual a las oportunidades. Podríamos decir que este enfoque no considera la dimensión de género como categoría significativa para el abordaje e interpretación de los problemas, esto se traduce en empresas gender-blind (Caprile, 2012:6). Según autores como García Calvente et al. (2010:45) esta omisión suele producirse como consecuencia de una falta de formación y concienciación en materia de género.

Generalmente, desde esta perspectiva se niega que existan desigualdades de género en la empresa. Y cuando reconocen alguna situación de desigualdad parten de argumentos como que las mujeres no han sido socializadas en el mundo de las empresas y, por lo tanto, no conocen las reglas del juego; o que carecen de la formación necesaria y las habilidades para competir en el lugar de trabajo o asumir posiciones de liderazgo; o otros argumentos, como el que transcribimos a continuación, que fue repetido en diversas entrevistas por parte de distintos representantes sindicales, y que explicaría, desde esta primera perspectiva, la desigual presencia de mujeres en diferentes categorías laborales en las empresas químicas.

RS5 - Es normal y lógico que no haya mujeres trabajando de operarias, porque en los ciclos formativos tampoco están, si no hay... No podemos poner a chicas si no existen. Además, estar en planta es un trabajo de hombres, estás en contacto con óxido de etileno, es un cancerígeno A2 [En la Escala CMP, Concentración máxima permisible ponderada en el tiempo, que mide la cancerosidad de los productos químicos]. Por ejemplo, las mujeres embarazadas o en lactancia, no pueden estar en ese trabajo, se las considera no aptas.

E - En los estudios de química, por ejemplo, hay muchas chicas.

RS5 - Entones es una cuestión de tiempo, ¿no? Ya llegarán.

(Transcripción Representante Sindical 5)

Así pues, cuando se adopta este enfoque sobre el género y la igualdad de género, es difícil que las empresas emprendan alguna medida para alcanzar, y aún menos para fomentar, la igualdad entre mujeres y hombres. Dentro de este tipo de empresas, las acciones que se emprenden en materia de igualdad, cuando las hay, van encaminadas a garantizar a nivel formal, es decir en el redactado del convenio, la igualdad de oportunidades y hacen poco para cambiar los factores sistémicos de desigualdad dentro de las organizaciones. Desde esta perspectiva, además, no se contempla la posibilidad de establecer medidas de acción positiva 
ni programas específicos para mujeres. Este tipo de empresas se corresponden con las más pequeñas, las más masculinizadas, y las que no disponen de plan de igualdad. Sus representantes las describen del siguiente modo:

Es que esto es una empresa pequeña, tradicional, a la antigua, de toda la vida.

Piensa que en el comedor aún hay espacios separados para jefes y para trabajadores, y también hay vestuarios de jefes y vestuarios de trabajadores (...). Si somos así, el tema de las mujeres, ipues aún peor! (Transcripción Representante Sindical 2)

La segunda perspectiva pasa de la eliminación de la diferencia a la valoración de la diferencia, es decir, dar valor a lo femenino. Desde esta perspectiva se conceptualiza el género como aquellas diferencias de socialización entre hombres y mujeres, que se hacen evidentes en las identidades de género. Desde esta perspectiva, las mujeres están en desventaja debido a los estilos de trabajo, las habilidades y los atributos asociados con lo femenino, que no son reconocidos ni valorados en los puestos de trabajo. Se entiende la igualdad de género dentro de una diversidad más amplia, reconociendo el género como una de las muchas diferencias importantes entre los trabajadores. Las estrategias de intervención incluyen la sensibilización y la preparación para promover la tolerancia y la comprensión de la diferencia. Otras iniciativas se centran en demostrar cómo actividades tradicionalmente femeninas o estilos, tales como escuchar, colaborar, fomentar, etc. son un complemento beneficioso para el conjunto de la empresa. Estos conocimientos pueden dar lugar a cambios importantes en las normas y las prácticas culturales, reconociendo los talentos y las contribuciones que las mujeres suelen aportar al trabajo. No hay duda que este tipo de intervenciones crean conciencia y pueden propiciar más tolerancia y flexibilidad. Si bien éste es un paso importante para ampliar las oportunidades para las mujeres, también tiene sus limitaciones. Al concentrarse en las diferencias, la puesta en práctica de este enfoque puede reforzar los estereotipos de género. Creemos que este enfoca ignora el poder de la imagen masculina que subyace en los modelos aceptados de éxito, liderazgo y visión empresarial. Las mujeres que promulgan un estilo femenino, aun cuando sus aportaciones son reconocidas y aplaudidas, ven que sus esfuerzos son casi invisibles o valorados de una manera muy marginal. La mayor barrera para el logro de la igualdad de género en este marco es que no pone en duda la diferencia jerárquica existente entre hombres y mujeres ni la diferencia de valoración entre lo masculino y lo femenino.

A propósito de esta segunda perspectiva, transcribimos el siguiente fragmento, que ejemplifica muy bien la postura de la empresa respecto a la igualdad de género:

Está bien entender las diferencias entre hombres y mujeres, pero no sólo. En la empresa valoramos mucho la diferencia, diferencias de razas, de nacionalidades... y ser hombre o mujer es una diferencia más. Es una cuestión ética, no hay que tratar mal a nadie por el hecho de ser diferente, esto lo valoramos mucho, tenemos varios cursos de formación sobre estos temas, que son obligatorios. Y aquí a las mujeres se las cuida muy bien. (Transcripción Representante Sindical 8)

La tercera perspectiva se centra en las barreras estructurales. El género, en este marco, se define en términos de diferencias entre mujeres y hombres, pero redirige la atención de las diferencias de características personales a las estructuras diferenciales de oportunidades que crean un campo de juego desigual. Este marco apunta a la segregación de ocupaciones, puestos de trabajo, formas de contratación, procesos de evaluación y promoción, que están sesgados en contra de mujeres y obstaculizan su avance, el llamado techo de cristal, glass cieling, como muchas autoras y autores apuntan (Anker, 1998; Torns et al., 2007; Cebrián y 
Moreno, 2008; Rubio, 2008). El objetivo de este enfoque es la creación de igualdad de oportunidades mediante la eliminación de barreras discriminatorias propias de las estructuras y los procedimientos de la empresa. Las intervenciones en este marco tienden a ser legalistas y basadas en políticas. Incluyen, por ejemplo: iniciativas de acción positiva, revisión de los procedimientos de contratación, políticas de promoción más transparentes y mejor comunicadas, diseñadas para garantizar la igualdad, directrices de prevención del acoso sexual, así como provisión de prestaciones laborales y familiares, políticas de conciliación, etc. Estas políticas e intervenciones estructurales contribuyen a mejorar las oportunidades de las mujeres y son una parte fundamental de cualquier iniciativa a favor de la igualdad de género. Sin embargo, también creemos que son insuficientes para lograr beneficios duraderos porque tienen poco efecto directo sobre las reglas y las prácticas informales que organizan las dinámicas laborales. En ausencia de un cambio cultural en la organización, las estructuras y las políticas no pueden, por su propia cuenta, crear una organización equitativa.

\section{CONCLUSIONES PRELIMINARES}

Los resultados del análisis realizado nos permiten apuntar dos grandes ideas a modo de conclusiones. Por un lado, destacar que, pese al avance en la incorporación progresiva de contenidos relacionados con la igualdad entre mujeres y hombres, esta incorporación es lenta y limitada. Por otro lado se nos hace necesario intentar explicar esta lentitud e incorporación limitada. Esta segunda conclusión es la que requiere más explicación y, consideramos, es fruto del enfoque dominante sobre la dimensión de género en las empresas. La literatura existente muestra el papel que juega el género en la dinámica de las empresas y, correlativamente, el impacto de la dinámica organizativa en el mantenimiento o transformación de los roles, estereotipos e identidades de género. A nuestro entender, según la concepción que se tenga del género y de la igualdad en las empresas, éstas desarrollan unas prácticas u otras en relación a la igualdad entre mujeres y hombres. Así, creemos que la limitada incorporación de contenidos que tienen que ver con las desigualdades o discriminaciones por razón de género es fruto de la manera de considerar el género en las organizaciones.

Respecto a la primera conclusión, queremos recordar cuáles son las materias con contenidos de género que se han ido incorporando a la negociación colectiva. En este texto las hemos presentado agrupadas en seis bloques: acceso al empleo, la contratación y la promoción en la empresa; maternidad, paternidad y salud laboral; clasificación profesional y retribución salarial; conciliación de la vida profesional, personal y laboral; violencia de género y acoso sexual y acoso por razón de sexo. En ellos se incluyen temas como el acceso al empleo, la promoción profesional, la formación, la conciliación, la igualdad retributiva, la seguridad y la salud en el trabajo, el acoso sexual y el acoso moral, el lenguaje no sexista, la contratación, suspensión y extinción del contrato, la movilidad funcional y geográfica, la prevención de riesgos laborales, etc. Si analizamos los contenidos de estos bloques vemos que las medidas que se introducen en los convenios en relación a la igualdad de género son de dos tipos: 1) medidas que dan respuesta a problemáticas específicas de las mujeres (conciliación, maternidad, lactancia...) y 2) medidas que tratan de paliar consecuencias que reciben las mujeres (violencia de género, acoso sexual y por razón de sexo...). Consideramos que estas medidas no corrigen las reglas, ni las prácticas informales, ni las dinámicas laborales injustas y que, por lo tanto, no son suficientes para un cambio cultural en la organización que cree una organización equitativa. Por supuesto que las medidas 
introducidas suponen un avance para la mejora de las condiciones de vida en el trabajo, pero su eficacia es limitada.

Además, en la mayoría de convenios se tienden a reproducir los textos legales, transcribiendo idénticamente la redacción del Estatuto de los Trabajadores, la LOIEMH o la LOMPVIG, sin introducir apenas modificaciones, y actualizando los contenidos de acuerdo a las novedades legales. En otras palabras, en los convenios hay una tendencia a asumir el principio de igualdad, pero esta asunción no se manifiesta en medidas de contenido concreto.

En lo referente a las empresas, hemos encontrado que éstas tienen, mayoritariamente, un enfoque del género tradicional. Entendemos que para conseguir actuaciones verdaderamente dirigidas a la promoción de la igualdad por razón de género, se requiere un enfoque que vaya más allá de los tres presentados. Mantenemos nuestra hipótesis que sin una concepción del género más allá de las tres citadas será difícil avanzar en la incorporación de contenidos en los convenios que hagan cambiar realmente la situación de las mujeres en las empresas. Esto no quiere decir que no sea conveniente y necesario lo que ahora se está haciendo. Sólo apuntamos que los cambios que estamos describiendo y los contenidos incorporados en materia de igualdad no dejan de ser medidas funcionales para un sistema basado en la división sexual del trabajo que sigue sin ser suficientemente cuestionado.

Consideramos posible otro enfoque del género, una cuarta perspectiva que se centraría en los factores sistémicos subyacentes en las empresas que conducen a la desigualdad laboral. El género, desde esta perspectiva, es una construcción social y va más allá: no trata de mujeres o de discriminación, trata de la propia empresa, que está inherentemente "generizada". Después de haber sido creadas, en gran parte, por y para los hombres, los sistemas de organización, las prácticas de trabajo, las estructuras y las normas tienden a reflejar la experiencia masculina, los valores masculinos y las situaciones de la vida masculina. Como resultado de ello, todo lo que consideramos normal y habitual en el trabajo tiende a favorecer a los hombres, unos privilegios que son social y culturalmente atribuidos a los hombres. El problema de la igualdad de género en este cuarto enfoque se basa en suposiciones muy arraigadas, a menudo incuestionables, que dirigen el comportamiento y las prácticas de trabajo en el seno de la empresa. Estas suposiciones parecen neutras y sin consecuencias, pero a menudo tienen un impacto diferenciado sobre hombres y mujeres. Por ejemplo, un supuesto de género que subyace en la vida de las empresas es la regla informal que el tiempo empleado en el trabajo, independientemente de la productividad, es una manera de medir el compromiso y la lealtad con la empresa. El trabajador más valioso es aquel que está dispuesto y deseoso de poner en primer plano el trabajo. Esta norma da privilegios a los trabajadores que no tienen responsabilidades en la esfera privada de sus vidas que les impidan aceptar una responsabilidad ilimitada en el trabajo. La imagen del trabajador ideal como aquel que no tiene responsabilidades fuera que interfieran en el compromiso con la empresa puede dar lugar a normas de trabajo, formales e informales, difíciles de conseguir no sólo para las mujeres, sino también para muchos hombres. Lo que rara vez se reconoce, sin embargo, es que también puede tener importantes consecuencias negativas en el desarrollo empresarial. Estos prejuicios pueden dar lugar a prácticas ineficaces, costosas e ineficientes. Además, desde esta perspectiva se valora también el factor estructural de la desigualdad de género, no sólo dentro de la empresa, también fuera de ella. Si bien es cierto que este cuarto enfoque es prácticamente inexistente entre las empresas de la AEQT, sí que debemos citar el caso de una de las empresas que se aproxima en gran medida a esta visión. A través de una iniciativa innovadora e interesante, que centra la atención en la sociedad, va más allá de la empresa. No obstante, este ejemplo, a fecha marzo de 2014, no se ha llevado aún a cabo, precisamente por 
la catalogación de la empresa de "actuación de baja prioridad". Sin embargo, sí es un buen ejemplo de buenas ideas e intenciones:

Tabla 2: Ejemplo de actuación prevista en un plan de igualdad

\begin{tabular}{|l|l|}
\hline \multicolumn{2}{|l|}{ ACTUACIONES EN CENTROS EDUCATIVOS } \\
\hline Prioridad & Baja \\
\hline Objetivo & $\begin{array}{l}\text { Atraer el interés de las mujeres hacia el sector químico, especialmente hacia } \\
\text { puestos históricamente ocupados por hombres (Producción y Mantenimiento) } \\
\text { con el objetivo de aumentar el número de candidaturas femeninas a tener en } \\
\text { cuenta para ocupar estas vacantes. }\end{array}$ \\
\hline Descripción & $\begin{array}{l}\text { Realizar presentaciones, charlas, publicidad en Institutos y Centros de } \\
\text { educación, preferiblemente a cargo de mujeres de la compañía, nuevas o ya } \\
\text { existentes, con la colaboración de la Comisión de Igualdad. }\end{array}$ \\
\hline Colectivo destinatario & Estudiantes mujeres (último curso ESO) \\
\hline
\end{tabular}

Fuente: Elaboración propia a partir de datos del Plan de Igualdad BASF Española SL, período 2012-2014

Más allá de este caso minoritario, esta cuarta visión, no es la realidad de la AEQT. ¿Cuáles son las dificultades de este enfoque? En primer lugar, se trata de un proceso de cambio y aprendizaje a largo plazo. Si bien esto puede producir beneficios significativos tanto para la igualdad de género como para el desarrollo empresarial, no todas las empresas están dispuestas a implicarse en este cambio. En segundo lugar, puede ser difícil mantener la meta de la igualdad de género, ya que esta meta puede ser fácilmente eclipsada por objetivos más próximos, como mejorar la eficacia organizativa. Finalmente, en un contexto como el actual de crisis e inestabilidad económica, resulta aún más complicado para muchas empresas emprender cualquier acción "extra". Así se repite en muchos discursos de las personas entrevistadas:

Ahora la empresa no está para estas cosas. Estamos en concurso de creedores, ya lo estuvimos también hace dos años, no sabemos quien nos va a comprar, cada vez. somos menos trabajadores... La empresa no quiere más lios. (Transcripción Representante Sindical 9)

Se tendría que dar una revisión cuidadosa para asegurar que el personal y los gerentes reconozcan y entiendan las implicaciones de los cambios introducidos para alcanzar la igualdad de género.

\section{BIBLIOGRAFÍA}

ALEMANY, C. (2006). Igualdad de oportunidades y negociación colectiva en la Unión Europea. Convenios Españoles seleccionados. Fase II. Unión Europea: EUROFOUND Fundación Europea para la Mejora de las Condiciones de Vida y de Trabajo.

ANKER, R. (1997). "Theories of occupational segregation by sex: An overview", en International Labour Review, 136 (3): 315-339.

ARENAS, M. (2010). "El estado de la negociación colectiva en materia de planes de igualdad", en Aranzadi Social: Revista Doctrinal, núm. 22, vol. 2.

CAPRILE, M. (coord.) (2012). Guía práctica para la inclusión de la perspectiva de género en los contenidos de la investigación. Madrid: Fundación CIREM.

CEBRIÁN, I. y MORENO, G. (2008). "La situación de las mujeres en el mercado de trabajo español. Desajustes y retos”, Economía Industrial, 367: 121-137. 
COMISIÓN EUROPEA (1998). 100 Palabras para la igualdad. Glosario de términos relativos a la igualdad entre hombres y mujeres. Luxemburgo: Oficina de Publicaciones Oficiales de las Comunidades Europeas.

CONFEDERACIÓN SINDICAL INTERNACIONAL (2008). Informe sobre la Brecha Salarial de Género. Bruselas: ITUC-CSI-IGB.

DILLA, M. J. (2011). "Maternidad, paternidad y salud laboral". En UGT e Instituto de la Mujer (eds.) Análisis de medidas y planes de igualdad en la NC. Madrid: CEC UGT.

DIRECCIÓ GENERAL D'IGUALTAT D'OPORTUNITATS EN EL TREBALL Y GABINET TĖCNIC DEL DEPARTAMENT DE TREBALL (2010). Dones i treball. Publicació estadística del Departament de Treball 2009. Barcelona: Departament de Treball.

DIRECCIÓ GENERAL D'IGUALTAT D'OPORTUNITATS EN EL TREBALL Y GABINET TĖCNIC DEL DEPARTAMENT DE TREBALL (2011). Dones i treball. Recull estadístic 2010. Barcelona: Departament de Treball.

DURÁN, M. A. (1986). La jornada interminable. Barcelona: Icaria.

ELY, R. y MEYERSON, D. (2000). "Theories of Gender in Organizations: A New Approach to Organizational Analysis and Change". En B. Staw y R. Sutton (eds.) Research in Organizational Behaviour. Greenwich: CT JAI Press.

ERRO, M. y SANZ DE PABLO, P. (2009). La Igualdad de Género en los Convenios Colectivos. Vitoria: Defensoría para la Igualdad de Mujeres y Hombres.

GARCÍA CALVENTE, M. M. et al. (2010). Guía para incorporar la perspectiva de género a la investigación en salud. Sevilla: Escuela Andaluza de Salud Pública.

GARCİA QUIÑONES, J. C. (2011). "El acceso al empleo, la contratación y la promoción en la empresa". En UGT e Instituto de la Mujer (eds.). Análisis de medidas y planes de igualdad en la NC. Madrid: CEC UGT.

INSTITUT D'ESTUDIS AUTONÒMICS (1998). Comentaris sobre l'Estatut d'Autonomia de Catalunya. Barcelona: Generalitat de Catalunya.

IZQUIERDO, M. J. (1998). El malestar en la desigualdad. Madrid: Cátedra.

LEY ORGÁNICA 3/2007, de 22 de marzo, para la Igualdad Efectiva de Mujeres y Hombres. BOE número 71, 23/3/2007: 12611-12645

LOUSADA, J. F. (2008). El principio de igualdad en la negociación colectiva. Madrid: Ministerio de Trabajo e Inmigración.

MINGO, M. L. (2007). "Situación de los derechos laborales de las mujeres víctimas de violencia de género en España. Evolución legislativa, contenido, protección y posibles líneas de actuación", en Revista del Ministerio de Trabajo y Asuntos Sociales, núm. extraordinario Igualdad de oportunidades para todos.

OIT (2008a). ABC de los derechos de las trabajadoras y la igualdad de género. Ginebra: Oficina Internacional del Trabajo.

OIT (2008b). Global Wage Report 2008/09: Minimum wages and collective bargaining: Towards policy coherence. Ginebra: Oficina Internacional del Trabajo.

PASTOR, I. (2008). Dones i Homes a la URV. Tarragona: Universitat Rovira i Virgili.

PONTÓN, P. y PASTOR, I. (2013). "La negociación colectiva como herramienta para alcanzar la igualdad de género en el trabajo", en XI Congreso Español de Sociología, Madrid.

REY MARTÍNEZ, F. (2000). "El principio de igualdad y el derecho fundamental a no ser discriminado por razón de sexo", en Diario La Ley, vol. 1, núm. 27.

RUBIO, F. (2008). La Bastida. Desigualtats de gènere. Mercat de treball. Barcelona: Fundació Surt.

SERRANO, R. (2014). L'eliminació de l'esquerda salarial de gènere des de la negociació collectiva. Conferencia presentada en el Consell de Treball Econòmic i Social de Catalunya, Barcelona, 26/02/2014.

SOBRINO, G. M. (2011). "El acoso sexual y el acoso por razón de sexo". En UGT e Instituto de la Mujer (eds.). Análisis de medidas y planes de igualdad en la NC. Madrid: CEC UGT.

SUPIOT, A. (2008). Derecho del Trabajo. Buenos Aires: Heliasta.

TORNS, T. (2007). Les dones i el treball: mites i certeses. Barcelona: Institut Català de les Dones. 
UGT (2013). Las políticas de recorte acentúan la desigualdad salarial y social entre mujeres y hombres. Informe sobre desigualdad salarial. Madrid: UGT.

UGT e Instituto de la Mujer (eds.) (2011). Análisis de medidas y planes de igualdad en la NC. Madrid: CEC UGT.

WEBB, B. y WEBB, S. (2004). La Democracia industrial. Madrid: Biblioteca Nueva. Fundación Francisco Largo Caballero.

WINDMULLER, J. P. (1989). Nueva consideración de la negociación colectiva en los países industrializados. Madrid: Ministerio de Trabajo y Asuntos Sociales.

\section{Breve currículo:}

\section{Paloma Pontón Merino}

Máster en Antropología Urbana (Universitat Rovira i Virgili, 2010) y licenciada en Periodismo (Universitat Autònoma de Barcelona, 2007), actualmente desarrolla su tesis como becaria predoctoral del programa de doctorado en Economía y Gestión de Empresas de la Universidad Rovira i Virgili de Tarragona sobre la igualdad de oportunidades entre mujeres y hombres en la empresa privada, y su vinculación con los convenios colectivos y la negociación colectiva, centrándose en el estudio de caso de la industria química del Camp de Tarragona. Ha trabajado desde 2007 en distintas universidades catalanas (Universitat Autònoma de Barcelona, Universitat Pompeu Fabra y Universitat Rovira i Virgili), en ámbitos relacionados con la documentación, la historia, la memoria oral, la desigualdad de género y las políticas de igualdad.

\section{Inma Pastor Gosálbez}

Profesora titular de Sociologia en el Departamento de Gestión de Empresas de la Universitat Rovira i Virgili y doctora en Sociología por la Universitat Autònoma de Barcelona. Actualmente dirige la Red Jean Monnet G-NET, Equality training network: EU contributions to gender mainstreaming and citizenship del programa Erasmus+ de la UE. Coordina el equipo español del proyecto EQUALITY Strengthening Women Leadership in Latin American HEI's and Society financiado por la Comisión Europea en el programa Alfa III. Dentro del Plan Nacional I+D+i dirige el proyecto La participación laboral de las mujeres. El caso de las spin-off universitarias en España. Es la directora del Observatorio de la Igualdad de la URV. Entre 2011 y 2014, ha coordinado el módulo Jean Monnet Integración europea y género. Premio a Tesis Doctorales del Consejo Económico y Social de España por ¿La gestión privada en la Administración Pública? El caso de los servicios sanitarios hospitalarios de Cataluña. 